\title{
The options for the future production of the medical isotope ${ }^{99} \mathrm{Mo}$
}

\author{
Steven C. van der Marck • Arjan J. Koning • \\ Kevin E. Charlton
}

Published online: 11 June 2010

(C) The Author(s) 2010. This article is published with open access at Springerlink.com

There is a shortage of medical isotopes in the world today. Two of the most important isotope producing reactors, the National Research Universal (NRU) reactor in Canada and the High Flux Reactor (HFR) in the Netherlands, are currently under repair. The main consequence is that the supply of ${ }^{99} \mathrm{Mo}$, the workhorse isotope of nuclear medicine, is far below the medical demand. This demand comes from $>30$ million patients worldwide that are diagnosed each year using ${ }^{99 \mathrm{~m}} \mathrm{Tc}$, the daughter isotope of ${ }^{99}$ Mo. Supply shortages will remain the case until these two reactors are returned to service. However, both these reactors are close to 50 years old, as are the three other main isotope producing reactors (BR2, Belgium, OSIRIS, France and SAFARI, South Africa, Fig. 1). Since it is expected that the clinical demand for ${ }^{99 \mathrm{~m}} \mathrm{Tc}$ will remain strong for decades to come $[1,2]$, the remaining life time of these reactors is too short. The future of a significant part of nuclear medicine is therefore dependent on new reactors being built, or on new technologies being developed.

In several countries, the present shortage has given rise to studies on possible ways to resolve the problem. In Canada, it was originally planned to replace the NRU by two so-called MAPLE reactors, but that project was discontinued for technical reasons [3]. Subsequently, at the initiative of the Canadian Government, an independent expert panel reviewed a large number of different proposals for ${ }^{99}$ Mo production, in order to advise on the way forward [4]. In the USA a committee investigated options to move away from the current use of highly enriched uranium

S. C. van der Marck $(\bowtie) \cdot$ A. J. Koning $\cdot$ K. E. Charlton

Nuclear Research and Consultancy Group,

Westerduinweg 3,

1755 ZG Petten, the Netherlands

e-mail: vandermarck@nrg.eu
(HEU) as target material for ${ }^{99}$ Mo production [5]. In the Netherlands, a new multipurpose reactor Pallas [6] has been proposed. This prompted the Dutch government to commission an independent review of all possibilities to produce ${ }^{99} \mathrm{Mo}$ in the future [7].

Such an important issue as the production of ${ }^{99} \mathrm{Mo}$ has political, economic and scientific aspects. In this editorial we focus on a scientific comparison of all the options, using the results of the independent committees as a basis. First we discuss the current technology of irradiating HEU plates in reactors. Then we describe the possible alternatives for ${ }^{99}$ Mo production in four broad categories: molybdenum targets in reactors, target plates in accelerators, ${ }^{99} \mathrm{Mo}$ extraction from liquid reactors and the replacement of the HEU targets by low enriched uranium (LEU). Finally we present conclusions, which are supported by the independent reviews mentioned above.

\section{Current technology: uranium targets in a reactor}

Almost all ${ }^{99}$ Mo production today comes from research reactors. Targets containing uranium are placed inside the reactor, where neutrons cause fission of ${ }^{235} \mathrm{U}$ atoms inside the target. Many isotopes are formed by these fission processes and these include ${ }^{99} \mathrm{Mo}$, so-called fission product ${ }^{99}$ Mo. After about 1 week of irradiation, the targets are taken from the reactor for chemical processing. The targets are dissolved in either an acid or alkaline solution and the ${ }^{99} \mathrm{Mo}$ is extracted chemically.

An important advantage of this technology is the high production rate. This production rate is determined by the combination of three factors: the number of neutrons available that cause fission (flux), the mass of ${ }^{235} \mathrm{U}$ available (target) and the probability of fission when a 
Fig. 1 The contribution of the five most important reactors to world ${ }^{99}$ Mo production

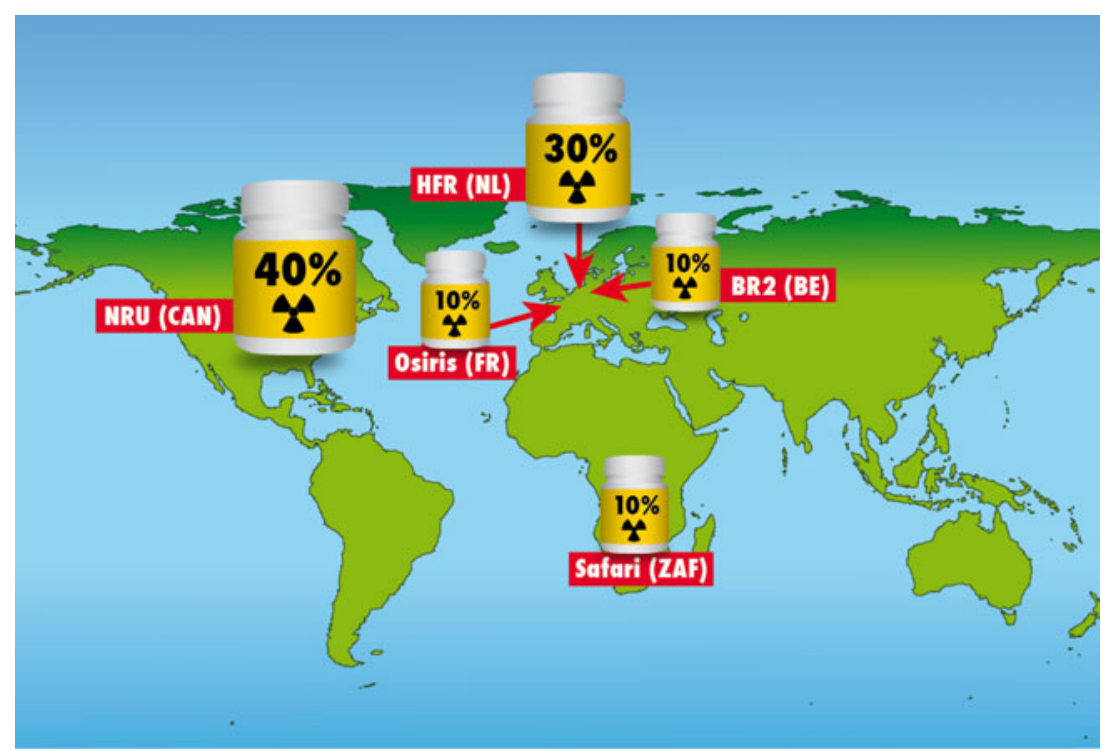

collision occurs (cross section). In the case of research reactors all three factors are large; the flux and the target space in research reactors are high in both cases and the natural probability of fission is also very high (see Table 1 for a comparison with the alternative processes). Another feature favouring fission is that a large proportion of the molybdenum produced is the desired ${ }^{99} \mathrm{Mo}$. This means that the material produced has a high level of radioactivity per gram of molybdenum (high specific activity).

There are also downsides. The chemical processing of targets creates liquid chemical waste that is highly radioactive and this must be processed and safely stored. Also, the procedure uses HEU, which is strategically sensitive material.

\section{Alternative 1: molybdenum targets in a reactor}

A first alternative is to irradiate molybdenum targets in a reactor. Neutrons can be captured by ${ }^{98} \mathrm{Mo}$ atoms to form ${ }^{99}$ Mo. The chemical processing after irradiation is relatively simple, as one only needs to dissolve the molybdenum target and there is no complicated extraction process.
Indeed this process was used for many years before the introduction of fission product ${ }^{99} \mathrm{Mo}$.

The production rate, however, is a problem. The probability that ${ }^{98} \mathrm{Mo}$ captures a neutron is rather low compared to ${ }^{235} \mathrm{U}$ fission (see Table 1). With the other factors that influence the production rate roughly equal, the production rate from a ${ }^{98} \mathrm{Mo}$ target is 250 times lower than fission, even for an expensive $100 \%$ enriched ${ }^{98}$ Mo target.

Perhaps more importantly, only a tiny fraction of the original molybdenum is converted to ${ }^{99} \mathrm{Mo}$ in the process. The fraction of ${ }^{99}$ Mo per gram molybdenum is 1,000 times lower compared to the current technology, leading to much lower radioactivity per gram of molybdenum. This low specific activity ${ }^{99}$ Mo product would not work with today's ${ }^{99 \mathrm{~m}}$ Tc generators and would cause a problem with some ${ }^{99 \mathrm{~m}} \mathrm{Tc}$ imaging kits. The design of the ${ }^{99 \mathrm{~m}} \mathrm{Tc}$ generators used to deliver the product to hospitals could be modified. This would have significant impact on the generator and imaging kit technology and it is unclear whether this is feasible to change.

To separate ${ }^{99}$ Mo from the rest of the molybdenum, there is research [8] into the possibility of using the recoil of the ${ }^{99} \mathrm{Mo}$ that is caused by the neutron capture of ${ }^{98} \mathrm{Mo}$. This
Table 1 Nuclear reaction types for the various proposals

\begin{tabular}{|c|c|c|c|}
\hline & & Reaction & $\begin{array}{l}\text { Cross section } \\
10^{-24} \mathrm{~cm}^{2} \text { (=barn) }\end{array}$ \\
\hline Reactor & $\begin{array}{l}\text { Current, alternative } 3,4 \\
\text { Alternative } 1\end{array}$ & $\begin{array}{l}\mathrm{n}+{ }^{235} \mathrm{U} \rightarrow{ }^{99} \mathrm{Mo}+\mathrm{xx}+2 \mathrm{n} \\
\mathrm{n}+{ }^{98} \mathrm{Mo} \rightarrow{ }^{99} \mathrm{Mo}\end{array}$ & $\begin{array}{l}(586 \times 6 \%=) 35 \\
0.14\end{array}$ \\
\hline Accelerator & Alternative 2 & $\begin{array}{l}\gamma+{ }^{238} \mathrm{U} \rightarrow{ }^{99} \mathrm{Mo}+\mathrm{xx}+2 \mathrm{n} \\
\gamma+{ }^{100} \mathrm{Mo} \rightarrow{ }^{99} \mathrm{Mo}+\mathrm{n} \\
\mathrm{p}+{ }^{100} \mathrm{Mo} \rightarrow{ }^{99} \mathrm{Mo}+\mathrm{p}+\mathrm{n} \\
\mathrm{p}+{ }^{100} \mathrm{Mo} \rightarrow{ }^{99 \mathrm{~m}} \mathrm{Tc}+2 \mathrm{n}\end{array}$ & $\begin{array}{l}0.16 \times 6 \% \\
0.16 \\
0.15 \\
0.20\end{array}$ \\
\hline
\end{tabular}

$n$ neutron, $\gamma$ photon, $p$ proton $x x$ other fission products 
method requires a target with a very high surface to volume ratio and needs to be scaled up. If this research is fruitful, the problem of the production rate still remains.

GE Hitachi Nuclear Energy (press release, 25 January 2010) will develop a ${ }^{99}$ Mo production method by placing molybdenum targets in commercial nuclear power reactors. As explained above, this method will have a low production rate. On the other hand, power reactors have the advantage of very large target volumes, so production of large quantities of very low specific activity ${ }^{99} \mathrm{Mo}$ is theoretically possible.

\section{Alternative 2: accelerators}

To avoid the use of reactors, accelerators are often proposed. When charged particles such as protons or electrons are accelerated to high enough energies, nuclear reactions can be induced in a target. The most commonly proposed reactions are listed in Table 1. In some cases, high energy photons are proposed instead of charged particles. The method using photon-induced fission of ${ }^{238} \mathrm{U}$ was recently proposed on the basis of computer simulations [9], but this has yet to be demonstrated and would need to be scaled up for mass production.

Accelerator methods using molybdenum as target material suffer from the same problem as molybdenum targets in reactors: the final product contains mostly inactive molybdenum, because only a tiny fraction of the molybdenum target is converted to ${ }^{99} \mathrm{Mo}$.

The last reaction shown in Table 1 does not produce ${ }^{99} \mathrm{Mo}$, but directly produces ${ }^{99 \mathrm{~m}} \mathrm{Tc}$. The 6-h half-life of ${ }^{99 \mathrm{~m}} \mathrm{Tc}$ implies that it is only possible to distribute it to a local regional area from a single production centre. Also, another form of technetium $\left({ }^{99 \mathrm{~g}} \mathrm{Tc}\right)$ is produced simultaneously with the ${ }^{99 \mathrm{~m}} \mathrm{Tc}$ in three times larger quantities (A.J. Koning, S. Qaim \& M.C. Duijvestijn, to be published). This additional inactive technetium could have negative effects upon some ${ }^{99 \mathrm{~m}} \mathrm{Tc}$ imaging kits.

An important advantage of accelerators is that they produce relatively less waste than reactors. Also, most accelerators require less investment than reactors.

The disadvantage of accelerators is the low production rate. For all the reactions listed in Table 1, the interaction probability is more than 250 times lower than the present fission process. In principle the flux of accelerated particles can be made higher than in a reactor, but this requires the development of new, even higher power accelerators. Perhaps more importantly, the useful irradiation volume (target size) in an accelerator is much smaller than in a reactor.

Therefore, the only remedy would be to build many accelerators. Independent expert panels have estimated that
500 accelerators would be needed, of a type that has yet to be developed. This would require a significant research effort and substantial investment with significant risks.

A US Scientific Advisory Committee did recommend, recently, the building of an accelerator for isotope production [10]. This advice, though, was for medical isotopes other than ${ }^{99} \mathrm{Mo}$, because there is an important category of medical isotopes that can be better produced using accelerators. The worldwide production level required for these isotopes is far lower than for ${ }^{99} \mathrm{Mo}$.

There are also proposals to couple an accelerator to a sub-critical reactor. The advantage would be that the flux produced by the accelerator is boosted by the chain reaction in the reactor. In essence, however, this option is building both a reactor and an accelerator, instead of just one of them.

\section{Alternative 3: liquid reactors}

Instead of placing uranium targets in a reactor or an accelerator, one can also dissolve uranium in water. When one fills a vessel of say 1501 with uranyl nitrate, this can be made critical as an aqueous homogeneous reactor, containing a few kilogram of uranium. Once a week, the solution could be transferred to a hot cell for processing and the molybdenum chemically extracted. Afterwards, the remaining solution has to be fed back into the reactor, otherwise the ${ }^{99}$ Mo yield per kilogram of uranium would be very low.

The principle of this technology has been proven, with a reactor power of the order of $200 \mathrm{~kW}$. Assuming that all of the ${ }^{99}$ Mo yield of a liquid reactor could be extracted every week, then, based on a comparison with present experience, around 20 liquid reactors would be required to produce the present world demand.

Advantages of liquid reactors are claimed to be an efficient use of neutrons, elimination of targets and lower costs.

The drawback of this technology is that it is not yet mature. An International Atomic Energy Agency (IAEA) report [11] lists many items that need further research, starting with determining whether this reactor type can be operated reliably for prolonged periods. The combination of the uranium solution and chemical processing has to be optimized, especially in view of the need to recycle the solution. This also means that the chemical cocktail in the reactor will be different after every production run. Since this reactor type is new, the license process for building and operating the reactor will be in uncharted territory. The suitability of the final ${ }^{99} \mathrm{Mo}$ product in existing ${ }^{99 \mathrm{~m}} \mathrm{Tc}$ generator designs is also not known. 
The companies Babcock \& Wilcox (press release, 26 January 2009) and Covidien have announced a project to develop this technology.

\section{Alternative 4: conversion from HEU to LEU}

There is the possibility to continue operations with more or less the current technology, but replacing HEU targets by LEU ones. LEU has by definition less than $20 \%$ of the fissile isotope ${ }^{235} \mathrm{U}$. The present targets for ${ }^{99} \mathrm{Mo}$ production, though, are so far still made of HEU, for the reasons outlined below.

When an HEU target is directly replaced by an equivalent $\mathrm{LEU}$ target, the number of ${ }^{235} \mathrm{U}$ atoms is reduced by a factor of 5 , and so is the ${ }^{99} \mathrm{Mo}$ production rate. To counter this effect, a different alloy of uranium and aluminium with increased uranium density can be used and thicker targets made. Such targets are currently used in Argentina for ${ }^{99}$ Mo production to serve the local market. Compared to the current technology, these targets have a two to three times lower ${ }^{99}$ Mo yield.

Materials are under development with even higher uranium densities. An example is the uranium silicide that is used as reactor fuel in the HFR, but it is not easy to chemically extract the molybdenum from this material. There are also alloys of uranium and molybdenum with very high uranium densities, but these alloys encounter the same problem as molybdenum targets: the initial molybdenum in the target also ends up in the final product leading to low specific activity ${ }^{99} \mathrm{Mo}$.

\section{Conclusions}

In summary, the current production rate of ${ }^{99} \mathrm{Mo}$ is based on the combination of high flux reactors, with significant target volume and the high natural probability of the nuclear fission reaction. All alternative techniques have to face the challenges of lower reaction rates and smaller target volumes. These can only be overcome by fundamental technical breakthroughs in areas such as separation technology, extremely high accelerator beam fluxes or special extraction techniques. It is unlikely that such breakthroughs will be achieved during the remaining life time of the reactors that currently produce ${ }^{99} \mathrm{Mo}$. Therefore, we arrive at the following conclusions:

1. The use of molybdenum targets leads to an activity per gram of molybdenum that is low. Even if this problem could be solved, the production quantities will be low.

2. Accelerators have a low production rate, so many of them would be needed to cover world supply. Direct production of ${ }^{99 \mathrm{~m}} \mathrm{Tc}$ has a lower activity per gram of technetium giving potential technical problems and has a logistic limitation because of the ${ }^{99 \mathrm{~m}} \mathrm{Tc}$ half-life of $6 \mathrm{~h}$.

3. Liquid reactors hold a promise for the future, but parts of the necessary technology need further research. The license process and the operational challenges and economics of this type of reactor are presently unknown. A significant number of liquid reactors would be needed to cover world supply.

4. Conversion of the HEU targets to LEU, using currently available technology, leads to a reduction in production capacity by a factor of $2-3$. Given the current crisis in production levels, it is difficult to see how this conversion can be implemented in the short term and without building additional reactor capacity.

Reactors will therefore remain necessary for the foreseeable future. The best way to secure the supply of ${ }^{99} \mathrm{Mo}$ for the more than 30 million patients each year is to build new research reactors to replace the old ones and to ensure sufficient total production capacity worldwide.

Open Access This article is distributed under the terms of the Creative Commons Attribution Noncommercial License which permits any noncommercial use, distribution, and reproduction in any medium, provided the original author(s) and source are credited.

\section{References}

1. Verbeek P. Report on molybdenum-99 production for nuclear medicine 2010-2020. AIPES Report, November 2008.

2. Technopolis Group. Radioisotopes in medicine. Foresight of the use of reactor isotopes until 2025. Technopolis Report, December 2008.

3. Labrie JP. Look beyond MAPLE reactors for isotope shortage answer. Canadian National Post, 28 July 2008.

4. Goodhand P, Drouin R, Mason T, Turcotte E. Report of the Expert Review Panel on Medical Isotope Production. Canada, 30 November 2009.

5. Whipple $\mathrm{C}$, et al. Medical isotope production without highly enriched uranium. National Academy of Sciences Report, ISBN 0-309-13040-9; 2009.

6. Pallas reactor. www.pallasreactor.eu/home/news. 2009.

7. Bode P, Delorme T. Productiewijzen voor radionucliden voor medische toepassingen met een onderzoeks-kernreactor en alternatieve technologieën. TU Delft report TUD-RID 2009-001, 11 February 2009.

8. Tomar BS, Steinebach OM, Bode P, Wolterbeek HT. Increasing the specific activity of medically useful isotopes through Szilard Chalmers reaction. Trans Am Nucl Soc 2008:880-1.

9. Ruth T. Accelerating production of medical isotopes. Nature 2009;457:536-7.

10. Hand E. Call to boost isotope supplies. Nature 2009;462:147.

11. Homogenous aqueous solution nuclear reactors for the production of Mo-99 and other short lived radioisotopes. IAEA-TECDOC1601, September 2008. 